\title{
DISSERTAÇÕES DE MESTRADO E TESES DE DOUTORADO/2011
}

\author{
Universidade Federal do Rio de Janeiro \\ Centro de Filosofia e Ciências Humanas \\ Instituto de Psicologia \\ Programa de Pós-graduação em Teoria Psicanalítica
}

\section{DISSERTAÇÕES}

Título: 0 trauma sexual do estupro em um grupo de mulheres quéchuas Autora: Ana Maria Guerrero Espinoza Orientadora: Regina Herzog Data de defesa: fev/2011

Este trabalho tem o propósito de pesquisar os possíveis modos de atuação psíquica do estupro. Apoiamo-nos para isso da experiência clínica com um grupo de mulheres camponesas quéchuas, estupradas durante o período de violência armada no Peru. Em primeiro lugar, fazemos um contexto social, entendendo que o sujeito é resultado de determinados processos e tempos que variam cultural e historicamente. Em segundo lugar, revisamos o caminho teórico freudiano sobre trauma sexual e sua relação com a neurose traumática, entendendo o estupro como situação traumática. Em terceiro lugar, revisamos uma proposta sobre a ligação entre sexualidade, passividade e agressão, para a partir daí dar passo às elaborações teóricas sobre estupro. Finalmente, propomos entender o estupro como uma vivência traumática de excessiva tensão, que inunda o eu e seus enunciados identificatórios, reativando o estado de desamparo. Sustentando-nos na experiência clínica, propomos a possibilidade de que estas vivências se convertam em um estado traumático que ative a identificação com o agressor, e que desde as posições ativas e passivas, derive em uma compulsão à repetição.

Título: Da determinação simbólica ao encontro com o real: como se produz a diferença a partir da repetição na experiência de uma análise? Autora: Cecília Moraes de Castro Leal Orientadora: Simone Perelson Data de defesa: mar/2011

A presente dissertação tem como proposta investigar a possibilidade de engendramento da diferença na experiência de uma análise, a partir da repetição em que se encontra capturado o sujeito. Com este objetivo, examina-se o conceito de repetição a partir das duas dimensões nele implicadas: a simbólica e a real. Inicialmente, privilegia-se a investigação da face simbólica da repetição. Observa-se que a presença de alguns trajetos aos quais o sujeito é insistentemente reconduzido em suas narrativas, e que marcam sua história, é inerente à própria estruturação do simbólico e está relacionada com a determinação do sujeito pelo discurso do Outro. A seguir, aborda-se a causa real da repetição, recorrendo-se a três noções que fazem a ela alusão: o conceito de pulsão de morte, de das Ding e de tiquê. Constata-se que a força motriz da repetição se refere 
a um excedente pulsional que resiste a qualquer esforço de significantização, e que se presentifica no simbólico como um cavo. Um cavo que, ao mesmo tempo, faz limite e incita à remissão significante. Através deste exame, evidencia-se que quando do encontro com o real é com a diferença radical que o sujeito se depara. E, a seguir, demonstra-se que o confronto com a falta no Outro é condição de possibilidade para este fugaz (re) encontro com a causa perdida do inconsciente. Por fim, trabalha-se a repetição em relação à experiência analítica. Para tanto, investigam-se as junções e disjunções entre este conceito e o de transferência - desde o início, fortemente articulados na obra freudiana recorrendo-se às contribuições de Lacan para desfazer o nó entre eles. Conclui-se que a transferência tem por efeito velar a castração do Outro e que, neste sentido, ela é um recurso contra a tiquê. Contudo, infere-se que é por meio da circularidade da demanda do analisante, isto é, dos significantes que retornam nela, que o analista pode ter acesso ao objeto em torno do qual eles gravitam. Deduz-se, então, que através das suas intervenções, o analista deve visar este resto de non-sense que assedia, nas entrelinhas, o discurso do paciente e que é assim que o sujeito poderá ser conduzido a se deparar com o inesperado, com o novo.

Título: A repetição e seus destinos na obra de Freud

Autor: Diego Frichs Antonello

Orientadora: Regina Herzog

Data de defesa: fev/2011

O objetivo da presente dissertação é realizar um mapeamento do conceito de repetição na obra freudiana. Buscaremos mostrar como a repetição atravessa o pensamento freudiano correlacionando-a com os conceitos fundamentais da psicanálise. Iniciamos com o Projeto de 1895, articulando a repetição com a vivência de dor e a vivência de satisfação, mostrando, no primeiro caso, indícios de uma repetição dolorosa fora do princípio de prazer e, no segundo, o fundamento do psiquismo da primeira tópica balizado pelo princípio de prazer. No segundo capítulo veremos como a repetição ganha o estatuto de conceito em 1914, onde é revelada pela transferência como o retorno do recalcado. Frente a complicações teóricas e novos indícios clínicos, Freud vai problematizar a ideia do princípio de prazer como exclusivo no funcionamento do psiquismo, passando a conferir uma importância capital à compulsão à repetição em 1920. A partir daí, vários temas presentes no Projeto de 1895 são retomados, dando um lugar de destaque à questão da dor e do trauma, conforme será indicado no último capítulo.

\section{Título: Os impasses do laço social}

\section{na psicose}

Autor: Fabio Malcher Martins de

Oliveira

Orientadora: Ana Beatriz Freire

Data de defesa: mar/2011

Esta dissertação explora os impasses do laço social na psicose, enfocando suas origens estruturais, além da forma como estes se atualizam. Inicialmente, há uma abordagem das conceituações freudianas da origem da vida civilizada, baseada no laço emocional, vendo em sua natureza libidinal uma valiosa possibilidade de articulação entre este conceito e o de laço social. Para Freud, a condição essencial 
para o estabelecimento de laços duradouros é uma renúncia de ordem pulsional. Segundo Lacan, o laço social acarreta perda de gozo, sua localização em significantes. Destaca-se, sobretudo, a dimensão de sacrifício, cuja origem estaria na renúncia ao incesto pelos assassinos do pai primevo, o que constitui a superação da horda primeva pelo totemismo. Esta ilustração mítica freudiana do início da civilização, marcada pelo crime primordial, é retomada por Lacan, sendo o significante Nome-do-Pai o representante, no psiquismo, de tal morte, consequentemente, do Pai simbólico; tal significante é forcluído na psicose. Pelas características particulares do Nome-doPai, sua forclusão acarreta dificuldades na regulação do gozo, logo, no laço social. $\mathrm{O}$ encontro com a linguagem, momento lógico da incidência do significante, foi um eixo desta pesquisa, havendo aí um marco estrutural: introjeção ou forclusão do Nome-do-Pai, e constituição do Outro, alteridade concernida no laço social. Finalmente, há um caso clínico no qual se revela um quadro de grande desregulação de gozo, havendo um intenso trabalho psíquico de defesa, a partir de um delírio, com o intuito de barrar o Outro e buscar um novo posicionamento subjetivo que possa representar alguma abertura ao laço social.

\section{Título: $\boldsymbol{A}$ repetição no discurso}

\section{freudiano}

Autora: Jacqueline Carrilho Adêo Humel Antoun

Orientador: Joel Birman

Data de defesa: mar/2011

Essa dissertação pretende percorrer a noção de repetição no discurso freudiano. Entendemos que a repetição está presente ao longo do percurso freudiano e articulase com conceitos fundamentais, como: sintoma, pulsão, transferência e memória. Marcamos três momentos importantes: a articulação da repetição com a memória; as relações da repetição com a transferência e, o advento do conceito de pulsão de morte que teve como condição a noção de compulsão à repetição. Esse último momento reafirma o vínculo entre pulsão e repetição. A partir do segundo dualismo pulsional, a chamada virada dos anos 1920, acompanhamos as principais mudanças que aconteceram no campo teórico e clínico da psicanálise. Destacamos a formulação da segunda tópica - o papel do superego e o sentimento inconsciente da culpa - a revisão do conceito da angústia, a ênfase no desamparo, a novidade do masoquismo originário e a importância da alteridade que tenta explicar a constituição do sujeito e o advento da civilização.

Título: As posições subjetivas nas fórmulas da sexuação: uma leitura da lógica de Lacan a partir de Freud Autora: Jaqueline Ferreira Orientadora: Simone Perelson Data de defesa: mar/2011

Nas fórmulas da sexuação de Lacan, encontramos os conceitos da diferença sexual elaborados por Freud, mas que foram ampliados teoricamente com a noção da angústia de castração e dos gozos fálico e não-todo fálico, possibilitando que a relação entre os sexos seja da ordem dos semblantes. Neste estudo, a análise tem início com Freud, a partir da descoberta dos complexos de Édipo e castração e suas consequências psíquicas, tendo em vista a postulação da primazia fálica para ambos os sexos. Freud afirmará a importância 
da relação imaginária entre ter ou não ter pênis, atendo-se ao 'rochedo da castração': para a menina, na inveja do pênis e, para o menino, na ameaça de castração. Lacan, inicialmente, apresenta a teoria com referência no complexo de masculinidade, e eleva o falo como um significante da diferença sexual. Na relação entre os sexos, há uma mudança na teoria de Lacan, com a introdução do conceito de angústia e a entrada em funcionamento da função do vazio. Tal posição lhe permite ir além do complexo de Édipo, extraindo, assim, as coordenadas da sexuação. É como falta, como negativo, que o falo se constitui para os dois sexos. Lacan designará o encontro com o outro sexo como sendo da ordem de um semblante - o homem procura do lado da mulher o falo que lhe falta, permitindo que ela compareça como objeto do seu desejo, e a mulher, por sua vez, se faz desejar pelo homem no que ela não tem, mas consentindo em fazer semblante do falo que lhe falta. Para Lacan, do lado masculino, o gozo é fálico e, do lado feminino, o gozo é bipartido: fálico e não-todo fálico. Esse é o modo com que Lacan apresenta o masculino e o feminino nas fórmulas da sexuação, diante da ausência da relação sexual.

Título: 0 masoquismo das mulheres: fantasia masculina, semblante feminino

Autora: Joana Maia Simoni

Orientadora: Angélica Bastos Grimberg

Data de defesa: fev/2011

A presente dissertação investiga a relação do masoquismo com a feminilidade. Parte-se das elaborações freudianas sobre esta problemática, que aproximaram desde cedo os dois termos; embora, ao final de sua obra, Freud tenha feito ressalvas quanto a uma equivalência entre eles. Os conceitos de falo, castração e complexo de Édipo são trabalhados para caracterizar a inscrição feminina na ordem fálica. Em um segundo momento, a dissertação examina o conceito de masoquismo, distinguindo a pulsão masoquista da perversão. Como o pretenso masoquismo das mulheres tem lugar principalmente na esfera amorosa, o estudo volta-se para o amor e são analisadas as concepções freudianas e lacanianas acerca dos modos de amar masculino e feminino. A parte subsequente da dissertação aborda a dessimetria entre os sexos sob uma perspectiva lógica e leva-nos à impossibilidade da relação sexual. Conclui-se, com Lacan, que a peculiar posição das mulheres em relação à castração e à privação fornece as coordenadas de um modo de satisfação propriamente feminino, solidário da impossibilidade de dizer a mulher. Por fim, chega-se à definição do masoquismo das mulheres como uma fantasia masculina, que tem como correlato, para o estabelecimento da parceria amorosa, a assunção desse semblante por parte das mulheres, sendo muitas vezes o meio pelo qual acedem a um gozo Outro.

\section{Título: 0 tratamento do gozo no autismo: clínica psicanalitica e objetos autísticos}

Autora: Katia Alvares de Carvalho Monteiro Orientadora: Angélica Bastos Grimberg Data de defesa: mar/2011

Investigamos nesta dissertação o estatuto do objeto na clínica do autismo. Retiramos balizas da obra de Freud e dos ensinamentos de Lacan, em uma articulação com o 
campo da clínica. Partimos da premissa de que o uso dos objetos pelo autista não é aleatório ou sem propósito. Sustentamos que há um trabalho realizado por ele quanto ao tratamento dado aos objetos. O objeto torna-se um instrumento privilegiado nas invenções inéditas deste trabalho. $\mathrm{O}$ autista inventa com seus objetos. A partir de um caso clínico, escutado durante 16 anos, situamos a construção do objeto autístico, como uma via de refreamento do excesso pulsional. Acompanhamos a criação de seu duplo protetor, em sua função regulatória, que lhe permitiu a localização do gozo, e em seguida verificamos seu trabalho para extrair de lalangue um significante que situa seu saber-fazer com o gozo. Em nosso percurso, recorremos às descrições de Kanner (1943) e Asperger (1944) para as síndromes do Autismo Infantil Precoce e Psicopatia Autística, respectivamente. Dos preciosos comentários de Lacan acerca do autismo, extraímos balizamentos que inserem o autismo no campo das psicoses. A partir do mecanismo de foraclusão do Nome-do-Pai, realizamos uma leitura do conceito de objeto e abordamos as noções de duplo e lalangue, situando sua importância na clínica. Por fim, procuramos cernir o lugar que o analista ocupa na clínica do autismo, sustentando um lugar vazio de gozo, deixando-se regular pelo trabalho do sujeito, através de uma presença regulada seja nas sessões, seja nas oficinas.
Título: A problemática da identificação nos estados limites: uma 'falta de ser'?

Autor: Leandro Rafael Ferreira dos

Santos

Orientadora: Marta Rezende Cardoso

Data de defesa: fev/2011

O principal objetivo desta dissertação é investigar os mecanismos psíquicos envolvidos nos processos de identificação nos estados limites. Para tal, é destacada a relação entre o eu e o outro (interno e externo), com ênfase na dimensão traumática que estaria na base desta relação. Esta análise leva em conta, de maneira articulada, os aspectos narcísicos e edipianos implicados nessa problemática. Nos estados limites, a relação com o outro é marcada por um estado de "servidão" do ego ao objeto, indicador da predominância de uma dimensão narcísica no percurso identificatório desses sujeitos. Pressupõe-se precariedade quanto à constituição das fronteiras egoicas, excessivamente porosas nesses casos. Estes aspectos são explorados através das noções de introjeção e de incorporação, as quais se entrelaçam profundamente com a de identificação. Visa-se, assim, elaborar a questão dos limites da interiorização psíquica, considerando-se a possível presença, no mundo interno, de uma alteridade interna radical e inassimilável.

Busca-se, por fim, sustentar a especial relevância do mecanismo de identificação projetiva nos estados limites. Este mecanismo parece prevalecer e melhor descrever a particularidade quantos aos modos de identificação nessas situações clínicas nas quais a busca de si no e pelo outro constitui elemento essencial. 
Título: Adolescência atual: a "inação" como obstáculo à ação criativa

Autora: Lívia Franco Cavalcanti Orientadora: Marta Rezende Cardoso Data de defesa: fev/2011

Ao contrário dos casos de violência atuada e ruidosa das passagens ao ato, certos adolescentes mostram-se apáticos, desvitalizados, incapazes de fazer um gesto ou dar um passo em qualquer direção. É como se tivessem desistido da tentativa de inserção no mundo compartilhado. Isto se torna mais evidenciado nos casos de abandono escolar, paralisação diante da escolha profissional e inserção no mundo do trabalho, fenômenos muito frequentes nos adolescentes de hoje. Apesar de pretensa onipotência, esses sujeitos costumam recuar diante de quaisquer conflitos e dificuldades. O foco desta pesquisa é a investigação das possibilidades e dos impasses de constituição de uma ação criativa sobre a realidade externa, capacidade que se institui primordialmente na vida infantil e se instala, de forma mais consistente, na adolescência. É o encontro com uma realidade "suficientemente boa" que, além de colocar limites ao puro fantasiar, vai permitir a construção do sentido de realidade, validando a experiência subjetiva, e possibilitando o sentimento de existência subjetiva. Trata-se de explorar a dimensão da ação presente na passagem adolescente, sublinhando a sua importância e, também, os possíveis entraves que daí podem resultar. É sustentada a hipótese de que a patologia da inação - que, paradoxalmente, pode ser considerada uma "patologia do ato" - se institui como modalidade de defesa radical frente à impossibilidade de saída satisfatória da travessia da adolescência, evidenciando o fracasso no estabelecimento da possibilidade de uma ação criativa do sujeito em sua relação com o mundo externo.

\section{Título: O lugar do analista no tratamento das psicoses: as perspectivas de Freud e Lacan}

Autora: Maria Luiza Carvalho Silva

Zanotelli

Orientadora: Ana Beatriz Freire

Data de defesa: mar/2011

A presente dissertação versa sobre o lugar do analista no tratamento das psicoses, tendo como eixo de investigação as visadas teóricas de Freud e Lacan. Desenvolve-se em torno de um caso clínico, cuja solução, construída pelo sujeito, se tece pelo destacamento de um significante novo. Esta é a hipótese investigada, ou seja, a possibilidade de um sujeito psicótico destacar um significante com valor de nomeação, amarrando os três registros (R, S, I) e possibilitando uma estratégia suplementar de estabilização - no caso, um lugar no público, no social. Para tanto, aborda o conceito de transferência em Freud e seus desdobramentos no ensino de Lacan, cernindo os elementos estruturais que permitem falar de transferência nas psicoses, bem como os obstáculos e as possibilidades de manejo para o analista. Nesta direção, o estudo do conceito de objeto nas psicoses se impôs, na medida em que esta questão se coloca como a problemática desta clínica, assim como a questão do corpo, demonstrando, nos fenômenos corporais na psicose, o que acontece quando há outra via de acesso ao corpo que não a simbólica e metafórica, e que a constituição de um corpo próprio implica uma operação do significante sobre o gozo. 
Título: "Sou homem ou sou mulher?": sobre a sexuação na psicose

Autora: Rafisa Moscoso Lobato Rêgo

Orientadora: Simone Perelson

Data de defesa: fev/2011

Este trabalho teve como objetivo realizar um estudo a respeito do fato de uma paciente psicótica, em alguns momentos, afirmar ser homem, enquanto que em outros, se perguntar se ela é mulher ou homem. Questiona-se se o fato de Vera dizer ser homem seria uma ideia delirante ou se teria o estatuto de Metáfora Delirante para ela. Questiona-se também se Vera estaria inserida na partilha dos sexos e, se não estiver inserida, se poderíamos pensar em alguma relação entre o fato de ela dizer ser homem e o efeito de empuxo-à-mulher. Para refletir sobre essas questões recorremos às elaborações freudianas sobre o tema da psicose, mais especificamente sobre o delírio, assim como sobre o conceito de projeção. Recorremos também ao primeiro momento do ensino de Lacan sobre o desencadeamento e a estabilização da psicose, a partir de sua teorização sobre a foraclusão do Nome-do-Pai. As fórmulas da sexuação e o efeito de empuxo-à-mulher foram ainda elaborações da teoria lacaniana utilizadas em nosso estudo. Dessa forma, foi possível pensar que o delírio construído por Vera, por não lhe trazer uma estabilização, ainda não tem a função de uma metáfora delirante para ela, parecendo-nos uma ideia delirante. Já, em relação à partilha sexual, pensamos que, por não estar submetida à função fálica, Vera não está inscrita nessa partilha.
Título: Manejo clínico nos estados limites: construindo caminhos Autora: Raquel Rubim del Giudice Monteiro Orientadora: Marta Rezende Cardoso Data de defesa: fev/2011

A relação entre o eu e o outro constitui o cerne da problemática dos estados limites. A incapacidade de interiorizar o objeto, dentre outros fatores, faz com que o sujeito se encontre num estado de radical dependência ao outro, vivenciado, paradoxalmente, como intrusivo. Esse modo de relação tende a ser repetido na situação transferencial, exigindo do analista especial cuidado quanto ao seu manejo técnico. Suas intervenções não devem ser vivenciadas pelo paciente como invasivas, ao mesmo tempo, em que o analista deverá estar atento para ser por ele percebido como devidamente presente.

O objetivo central desta dissertação é justamente refletir sobre a questão do manejo clínico no processo analítico dos estados limites. Visando dar conta desta problemática são elaboradas as noções de "implicação" e "reserva" do analista, assim como a dimensão de contratransferência, a qual possui grande relevo no atendimento desses casos. Partindo desses elementos, esta pesquisa vem promover o aprofundamento e o desdobramento da noção de construção em análise, visando sublinhar o fundamental papel que desempenha este instrumento na clínica dos estados limites. A noção de construção é articulada à de figurabilidade, com a intenção de demonstrar como o recurso da construção, no contexto clínico, pode ser considerado como processo de criação de uma forma para as marcas traumáticas, via por meio da qual se pretende abrir caminho para a sua representação. 
Título: Dos objetos da pulsão ao

\section{analista como objeto}

Autora: Tatiana Holanda de Souza

Orientadora: Fernanda Costa-Moura

Data de defesa: fev/2011

Partindo do questionamento sobre o lugar do analista junto à economia pulsional do sujeito, o presente trabalho busca situar os fundamentos que levaram Lacan a aproximar o analista do conceito de objeto de forma tão basal em seu ensino. Com esse intuito, recorta-se a problemática concernente ao objeto da pulsão de modo a demarcar o objeto-resto que escapa de qualquer tentativa de predicação, denominado por Lacan como objeto a. Destacando a relevância deste objeto para o campo do sujeito, a pesquisa busca refletir sobre o trabalho analítico enfatizando o problema da transferência, uma vez que esta atualiza a presença deste objeto em negativo que é constitutivo do sujeito. Através da noção de demanda - que envolve o pedido, o apelo implicado em toda experiência analítica - , examina-se a forma singular como as demandas feitas no contexto analítico devem ser consideradas pelo analista implicado na ética da psicanálise. Demonstra-se que em oposição ao que é ordinariamente considerado, a demanda não implica um objeto próprio, adequado o qual a esta se referiria. A demanda implica e é correlata à falta de objeto no campo do sujeito que sucede pela operação da linguagem. Conclui-se, portanto, que como não há objeto próprio e adequado da pulsão, o modo como o analista irá acolher e responder às demandas do analisante tem incidência sobre a posição do sujeito por relação ao objeto e é o que distinguirá a práxis analítica de qualquer psicoterapia ou técnica de sugestão. 
TESES

Título: Sexuação e modalidades de gozo na clínica com mulheres psicóticas

Autora: Andréia da Silva Stenner Orientadora: Ana Beatriz Freire Data de defesa: jul/2011

Interrogamos se há alguma particularidade do fenômeno de feminização do gozo nas mulheres psicóticas. Nossa hipótese é de que o "empuxo-à-mulher" possa ser um tratamento do gozo cuja estruturação perpasse, necessariamente, pelas manifestações do "não-todo" feminino como a devastação e a erotomania, facetas, como conceitua Lacan, do gozo outro que não passa pela castração, portanto não regulado, louco, sem barra. Para isso, precisamos cernir algumas teses principais em Freud e Lacan. O que eles queriam dizer com castração, falo e função fálica, tomando os aforismas lacanianos: "A mulher não existe" e "não há relação sexual", como principais norteadores dessa escrita, bem como a tábua da sexuação a fim de colocar no centro de nossa discussão o que Lacan quis dizer sobre a diferença sexual. Utilizarnos-emos de casos clínicos a fim de averiguarmos como essas mulheres psicóticas se posicionam diante da diferença sexual e tratam o gozo que as invade seja pela via da devastação, da erotomania ou do “empuxo-à-mulher”. Perguntamo-nos se a devastação e a erotomania são modalidades de gozo que estruturem logicamente o "empuxo-à-mulher” como uma versão sexuada do gozo na psicose. Descobrir o estatuto da sexuação e demarcar as fronteiras desse gozo da não relação sexual, articulando-a ao gozo psicótico em sua junção/disjunção com o gozo feminino foi o que norteou nossa tese.
Título: Kakon: assassinatos imotivados na psicose Autor: Carlos Alberto Ribeiro Costa Orientadora: Ana Beatriz Freire Data de defesa: jul/2011

O presente trabalho traz como objeto de suas considerações os assassinatos imotivados na psicose. Em nossa aproximação desta questão resgatamos, a partir de Paul Guiraud e Jacques Lacan, o termo kakon - palavra grega para o "mal” —, para designar o mal-estar que, ao se apresentar ao psicótico, coloca-o em um estado de urgência. Partindo da experiência clínica com estes pacientes e retomando as descrições clássicas destes quadros temos como questão que move nosso trabalho os "casos kakon" - sua emergência, consequências e tratamento - em suas relações com a psicose. A abordagem desta questão nos conduzirá a pensar a articulação, na psicose, entre passagem ao ato e responsabilidade, assim como nos possibilitará interrogar a forma princeps de resposta concedida a estes casos pela sociedade: internação em Hospital de custódia e tratamento psiquiátrico. Com Freud e Lacan — que sustentam, desde a noção de pulsão, a inexistência de instintos assassinos ou criminosos, tomaremos posição contrária às formas de segregação que legitimam este tipo de resposta nomeada por Lacan, a partir de Gabriel Tarde, como "concepção sanitária da penalogia”. 
Título: Neurose traumática:

fundamentos e destinos

Autora: Gabriela Maldonado Borges

Orientadora: Marta Rezende Cardoso

Data de defesa: set/2011

O objetivo central desta tese é aprofundar a compreensão da neurose traumática, situando a sua origem e identificando as suas bases psíquicas. O conceito de trauma possui especial destaque no presente estudo, cuja referência teórica fundamental é a teoria freudiana, particularmente o modelo do segundo dualismo pulsional. A partir dele são destacadas a ideia de uma pulsão sem representação e a de uma situação de passividade radical do ego ante a invasão de um pulsional mortífero. A questão dos destinos psíquicos dos elementos “irrepresentáveis" é elaborada através de uma apreciação da teoria freudiana da memória, no interior da qual buscamos traçar uma articulação entre as noções de a posteriori e de compulsão à repetição. Esta articulação é construída por meio da análise, dentre vários outros tópicos, de uma das vicissitudes mais características da "memória" traumática: o sonho traumático. O desenvolvimento apresentado na tese busca sublinhar o papel essencial da dimensão de alteridade nos processos envolvidos na neurose traumática — alteridade, tanto interna, quanto externa. Procuramos demonstrar que a atividade de endereçar um testemunho sobre o vivido traumático a alguém revela-se fundamental, por abrir uma possibilidade de representação do “indizível” traumático. Paradoxalmente, estes elementos clivados insistem em "dizer-se", o que se configura como possibilidade de preservação da qualidade da vida psíquica.

\section{Título: Psicanálise e velhice}

Autor: Glória Maria Castilho

Orientadora: Angélica Bastos Grimberg

Data de defesa: jul/2011

Partimos da escuta de "idosos" no ambulatório NAI/Unati/Uerj: quedas, dores e esquecimentos frequentes rapidamente apreendidos como distúrbios e déficits pelo discurso médico vigente na área de saúde. Esta apresentação do mal-estar na cultura em nossa época recobre a complexidade de uma queixa na velhice, que implica a realidade psíquica. A escuta de "idosos" evidencia pontos de fixação de difícil dialetização e a decorrente pergunta acerca de como intervir em uma economia de gozo. Relatos frequentes de um sentimento de estranheza e a magnitude e concomitância das perdas relatadas conduziram à pergunta acerca da perturbação do luto na velhice. Para Lacan, a experiência do luto está do lado da privação e requer trabalho a partir da perda para situar-se do lado da castração. Tomando Hamlet e Ophelia da literatura universal e Frida, da literatura psicanalítica, situamos que apreender-se como falta é condição de possibilidade para que ocorra trabalho de luto e seja reinstaurado o circuito do desejo. Frases como "eu não faço falta" situam a função da angústia ao localizar a falta. Daí a importância do manejo da angústia sob transferência. Fragmentos de análises, frases de velhos que intervieram no campo social e dois velhos da literatura, Lear e Édipo, balizaram as indicações éticas acerca da irrupção do discurso analítico a cada travessia de um discurso a outro e o necessário remanejamento de gozo, compatível com alguma circulação da falta, traduzido em recortes clínicos, especialmente na leitura de um chiste produzido em análise. 
Título: Sujeito e estrutura: uma articulação ética

Autor: Marcos Eichler de Almeida Silva

Orientadora: Fernanda Costa-Moura

Data de defesa: jul/2011

O trabalho em questão se dedica a analisar a problemática do sujeito em psicanálise; especificamente, a relação e articulação do conceito de sujeito à noção de estrutura, objetivando demonstrar que é somente no seio da estrutura que é possível situar o sujeito em psicanálise, e que, além disso, é só em articulação com o sujeito que a noção de estrutura ganha seu peso devido no campo psicanalítico. A partir do fato de que a estrutura, enquanto formalismo, engendra uma lógica que estabelece as regras de composição e articulação entre seus termos constitutivos, põe-se candentemente em relevo a situação paradoxal do sujeito em psicanálise, conduzindo à pergunta acerca do lugar possível para o sujeito no seio de regras combinatórias que, por princípio, prescindiriam de qualquer subjetividade para operar. Evidencia-se, deste modo, que o estatuto do sujeito em psicanálise se enquadra irreconciliavelmente entre a determinação estrita e a liberdade plena - pois o sujeito é efeito da determinação inconsciente, mas, ao mesmo tempo, essa determinação não se limita a provocar efeitos necessários a partir de condições iniciais e constitui antes, de um só golpe, um determinismo que inclui a liberdade de escolha e uma "escolha forçada" que inclui o determinismo. Eis aí colocado, portanto, o problema de uma articulação entre determinismo e liberdade que possa balizar o campo da psicanálise - uma articulação que exclui tanto a liberdade pura de uma autoconsciência, quanto o determinismo estrito. Pretende-se enca- minhar a discussão dessas questões pela análise da especificidade da relação do sujeito do inconsciente com a categoria de alteridade, destacando seus aspectos formais e os efeitos dessa formalização. Relação que concerne, grosso modo, ao problema da determinação - e, igualmente, o da liberdade como sua contrapartida — como afirmação ou negação da necessidade causal entre um termo condicionante e um termo condicionado, que assim o é pela incidência de um termo condicionante que lhe é alheio, exterior. A torção imposta à noção de alteridade no campo psicanalítico permite ressituar essa oposição, de modo a sustentar que a articulação entre sujeito e estrutura implica um registro muito específico da ética. 